\title{
Intestinal Parasitic Infections and Iron Deficiency Anaemia among School Children in El Khalige Village, Dakhalia, Egypt
}

\author{
Ahmed M. Mahmoud ${ }^{1}$, Mohieddin Abdul Fattah ${ }^{2}$, Tarik I. Zaher ${ }^{1}$, \\ Sara A. Abdel-Rahman ${ }^{2}$, Nahed Mosaad ${ }^{1}$ \\ ${ }^{I}$ Tropical Medicine Department, Faculty of Medicine, Zagazig University, Egypt \\ ${ }^{2}$ Parasitology Department, Faculty of Medicine, Zagazig University, Egypt
}

Corresponding Author Sara Abdel-Rahman

Mobile: 01222268663

E mail: sarameram@yahoo.co $m$

Key words: anaemia, intestinal parasite, school children, Dakhalia, Egypt
Background and study aim: Intestinal parasitic infection and iron deficiency anaemia are still nowadays, an important public health problem worldwide, mainly in developing countries. The present study aimed to study the relationships between intestinal parasitic infections and iron deficiency anaemia in school children 612 yrs.

Patients and Methods: A cross-sectional study was performed among (102) school children at El Kalige Village-Dakahlia. Children having signs or symptoms related to other causes of microcytic hypochromic anemia such as thalassemia, diabetes mellitus, cancers, receiving chemotherapy or radiotherapy were excluded from the study. Examination of blood and stool were done for all children.

Results: The prevalence of parasitic infections was $37 \%$ of total 102 school children. Parasitic infection was subdivided into 3 major group; helminthes, protozoa and mixed infection. Overall, helminthes infection was more prevalent $22 \%$ compared with both protozoa infection $8 \%$ and mixed

\section{INTRODUCTION}

Parasitic infection is considered a major public health problem in children all over the world. In developing countries, low social and financial status of the individual leads to the increase in the prevalence of intestinal parasitic infections [1]. Epidemiological studies in several countries, has shown around 3.5 billion people affected globally; 300 million of them are ill, $50 \%$ of them being school age children [2]. In Egypt, the infection 8\%. Ancylostoma duodenale (9.8\%), Hymenolepis nana and Giardia lamblia (7.8\%), Strongyloides stercoralis (5.9\%) Entamoeba histolytica and Cryptosporidium $(3.9 \%)$ each and lastly, Enterobius vermicularis, T. trichura and Schistosoma mansoni with 2 cases each $(1.9 \%)$. The parasitic infection was higher in females $(52.6 \%)$ more than males $(47.4 \%)$ insignificantly. Anemia was mild in infected group with $\mathrm{Hb}$ (Mean \pm SD) $11.12 \pm 1.35 \mathrm{~g} / \mathrm{dl}$. $51 \%$ of selected children were anaemic. The prevalence of anemia was slightly highly non-significant prevalent among infected children $(52.6 \%)$ compared with non infected $(50 \%)$. Iron deficiency anemia (IDA) represents $88.5 \%$ of anemic cases in all children, $90 \%$ of anemic cases in the infected children and $87.5 \%$ of anemic cases in non infected children.

Conclusion: This study showed a high prevalence of parasitic infections among the children in the rural areas of Egypt and IDA is associated with intestinal parasitic infection.

intestinal parasites affect $56 \%$ of the school children [3].

Due to anaemia, growth retardation and some developmental and mental problems, parasitic infections are considered a dangerous health problem [4].

In children (0.5-5.0 yrs), hemoglobin level $<11 \mathrm{~g} / \mathrm{dl}$ and for children (12-15 yrs) hemoglobin level $<12 \mathrm{~g} / \mathrm{dl}$ is defined as anaemia [5]. 
Anemia is a nutritional disorder worldwide especially in children. In various less developed countries in both Asia and Africa, $40 \%$ of children are anemic. In the early periods of life of children, the Deaths reached 726,000 caused by iron deficiency, with the highest percentage in Africa and Southeast Asia [6].

Disturbance in the behavior of the children can be occurred due to chronic anemia, due to its hazard effect upon neurological development in infants and also reduced scholastic performance in children of school age. Rest-less legs syndrome is common in those with iron deficiency anemia, with several symptoms include swelling of the arms or legs, heartburn, vague bruises, vomiting, sweating, pallor and blood in stool [7].

The main treatment of anemia is by treatment of the underlying disease which in most cases leads to cure or at least improvement of anemia. So, World Health Organization depends upon regular deworming of school age children in its control strategy. Regular treatment reduces the intensity of infection and gives a protection to those already infected [8]. Therefore, this study was undertaken to investigate the prevalence of intestinal parasitic infections in school going children in El Khalige village despite the various precautional measures and also, the relationship between intestinal parasitic infections and iron deficiency anemias. The results will be taken by the school authority to help them to adopt deworming measures.

\section{PATIENTS AND METHODS}

\section{Study type:}

This study was a cross sectional prevalence study. The study was conducted from January to December 2016. The practical work was done at the Department of Tropical Medicine and the Medical Parasitology Department of the Faculty of Medicine, Zagazig University, Zagazig, Egypt.

\section{Study area}

The current study was performed at El Kalige Village lies 10 kilometers away from EL Mansoura city, the village supplied with a clean water supply and central sanitary sewage systems.

\section{Sample Size:}

The calculated sample size of the study was 102 children, using the following formula [9].

$$
\mathrm{n}=\frac{\mathrm{Z}^{2}+\mathrm{P}^{*}(1-\mathrm{P})}{\mathrm{d}^{2}}
$$

Where

$\mathrm{Z}=1.96$ for $95 \%$ confidence level.

$\mathrm{p}=$ expected prevalence of satisfaction $(0.50)$.

$\mathrm{d}=$ precision (Margin of error) $=0.05$

\section{Inclusion criteria:}

All children aged 6-12years attending EL-Khalige primary school were included in this study.

\section{Exclusion criteria:}

Children suspected to have signs or symptoms related to other causes of microcytic hypochromic anemia such as thalassemia, or chronic debilitating diseases as malignancy, chronic renal diseases, diabetes mellitus, immune diseases were avoided .

A full history through a special sheet was obtained by the investigator after interviewing the mothers of the selected children and receiving a questionnaire. The parents of the children completed consent forms, but because many of them refused to give information about their income, we could not interpret the socioeconomic standards and could not estimate the amount of taken iron in diet.

All selected children were subjected to the following, Full history taking including: Age, Gender, Residence, education attainment, socioeconomic status (father or mother occupation, household income), medical and drug history, complaint (diarrhea, abdominal pain, anorexia, nausea, vomiting and anal itching) pallor, jaundice, clubbing, organomegally and ascities.

\section{Collection of stool samples:}

The stool was examined macroscopically for the presence of blood and mucus or adult worm of helminths.

The stool was examined microscopically also for ova and cysts of intestinal parasites by direct wet smear which was done within twelve hours of the collection of the sample. Direct examination was performed by wet mount technique using saline, iodine and lacto phenol. In case of negative samples, concentration technique by formalin acetone sedimentation method was done [10]. Baermann's technique was used for demonstration of Strongyloides larva [11]. In addition modified acid fast staining was done for demonstrating coccidian parasites like Cryptosporidium, Isospora.

\section{Blood Collection and Determination of Iron Status:}

Test performance for Hemoglobin concentrations was done using the Cyanmethemglobin method to form the stable hemoglobin derivative 
cyanmethemoglobin. The Potassium Ferricyanide converts the Hemoglobin to Methemoglobin by the action of Potasium Cyanide and was standed for 3 minutes. For conversion of Hemoglobin to Cyanmethemoglobin, before the absorbance is measured against a reagents blank at a wave length of $540 \mathrm{~mm}$ using a Spectrophotometer [12].

Data were analyzed with SPSS version 21. The normality of data was first tested with one-sample Kolmogorov - Smirnov test. Qualitative data were described using number and percent. Association between categorical variables was tested by Chi-square test. Continuous variables were presented as mean $\pm \mathrm{SD}$ (standard deviation). The two groups were compared with Student ttest while more than two groups compared by ANOVA test. The significance's threshold is fixed at $5 \%$ level (p-value). P-values $<0.05$ were considered significant and $>0.05$ was insignificant. But $<0.001$ was highly significant.

Table 1: Comparison between infected and non-infected group regarding to gender, age and anemia for 102 school children aged 6-12ys

\begin{tabular}{|c|c|c|c|c|c|}
\hline \multirow{2}{*}{ Items } & \multicolumn{2}{|c|}{$\begin{array}{c}\text { Infected group }(\mathrm{n}=38) \\
(37 \%)\end{array}$} & \multicolumn{2}{|c|}{$\begin{array}{l}\text { Non-infected } \\
(n=64)(63 \%)\end{array}$} & \multirow[t]{2}{*}{$\begin{array}{l}\text { Test of sig. p- } \\
\text { value }\end{array}$} \\
\hline & No & $\%$ & No & $\%$ & \\
\hline \multicolumn{6}{|c|}{ Sex } \\
\hline Male & 18 & 47.4 & 26 & 40.6 & \multirow{2}{*}{$\begin{array}{c}\mathrm{X}^{2}=.442 \\
\mathrm{p}=.506\end{array}$} \\
\hline Female & 20 & 52.6 & 38 & 59.4 & \\
\hline \multicolumn{6}{|c|}{ Age/years } \\
\hline Mean \pm SD & \multicolumn{2}{|c|}{$8.94 \pm 2.19$} & \multicolumn{2}{|c|}{$9.18 \pm 1.82$} & \multirow{2}{*}{$\begin{array}{l}\mathrm{t}=.596 \\
\mathrm{p}=.553\end{array}$} \\
\hline Min-Max & \multicolumn{2}{|c|}{$6.00-12.00$} & \multicolumn{2}{|c|}{$6.00-12.00$} & \\
\hline \multicolumn{6}{|c|}{ Anemia } \\
\hline Anemic & 20 & 52.6 & 32 & 50.0 & \multirow{2}{*}{$\begin{array}{c}\mathrm{X}^{2}=.066 \\
\mathrm{p}=.797\end{array}$} \\
\hline Non anemic & 18 & 47.4 & 32 & 50.0 & \\
\hline
\end{tabular}

${ }^{*} \mathrm{p}$ value is significant when $\mathrm{p} \leq 0.05$

Table 2: Comparison between all selected children, infected and non infected children regarding to Iron deficiency anemia (IDA) and anemia

\begin{tabular}{|c|c|c|c|c|c|c|c|}
\hline \multirow[t]{2}{*}{ Items } & \multicolumn{2}{|c|}{ Total selectedchildren (102) } & \multicolumn{2}{|c|}{ Infected child (38) } & \multicolumn{2}{|c|}{$\begin{array}{l}\text { Non infected } \\
\text { children(64) }\end{array}$} & \multirow[t]{2}{*}{$\begin{array}{c}\text { Test of sig. } \\
\text { p-value }\end{array}$} \\
\hline & NO & $\%$ & NO & $\%$ & NO & $\%$ & \\
\hline IDA & 46 & 45 & 18 & 47.3 & 28 & 43.8 & \multirow{2}{*}{$\begin{array}{c}\mathrm{X}^{2}=.077 \\
\mathrm{p}=.962\end{array}$} \\
\hline Anemia & 52 & 51 & 20 & 52.6 & 32 & 50 & \\
\hline
\end{tabular}

$* p$ value is significant when $p \leq 0.05$ 
Table 3: Subtypes of parasitic infection and Comparison between them regarding to gender, age and anemia

\begin{tabular}{|c|c|c|c|c|c|c|c|}
\hline \multirow[t]{2}{*}{ Items } & \multicolumn{2}{|c|}{$\begin{array}{c}\text { Helminthes group } \\
(\mathrm{n}=\mathbf{2 2})(22 \%)\end{array}$} & \multicolumn{2}{|c|}{$\begin{array}{c}\text { Protozoal group } \\
(\mathrm{n}=8)(8 \%)\end{array}$} & \multicolumn{2}{|c|}{$\begin{array}{c}\text { Mixed group } \\
(\mathrm{n}=8)(\mathbf{8 \%})\end{array}$} & \multirow{2}{*}{$\begin{array}{l}\text { Test of sig. } \\
\text { p-value }\end{array}$} \\
\hline & No & $\%$ & No & $\%$ & No & $\%$ & \\
\hline \multicolumn{8}{|c|}{ Sex } \\
\hline Male & 10 & 45.4 & 6 & 75.0 & 6 & 75.0 & $\mathrm{P}=.483$ \\
\hline Female & 12 & 54.5 & 2 & 25.0 & 2 & 25.0 & $\mathrm{P}=.002$ \\
\hline \multicolumn{8}{|c|}{ Age/years } \\
\hline Mean \pm SD & \multirow{2}{*}{\multicolumn{2}{|c|}{$\frac{8.68 \pm 1.75}{600-1200}$}} & \multicolumn{2}{|c|}{$8.37 \pm 1.50$} & \multicolumn{2}{|c|}{$9.12 \pm 1.72$} & \multirow{2}{*}{$\mathrm{p}=.691$} \\
\hline Min-Max & & & & .00 & \multicolumn{2}{|c|}{$6.00-11.00$} & \\
\hline \multicolumn{8}{|c|}{ Anemia } \\
\hline Anemic & 12 & 54.5 & 4 & 50.0 & 4 & 50.0 & \multirow[b]{2}{*}{$\mathrm{P}=.041$} \\
\hline Non anemic & 10 & 45.4 & 4 & 50.0 & 4 & 50.0 & \\
\hline
\end{tabular}

* $\mathrm{p}$ value is significant when $\mathrm{p} \leq 0.05$

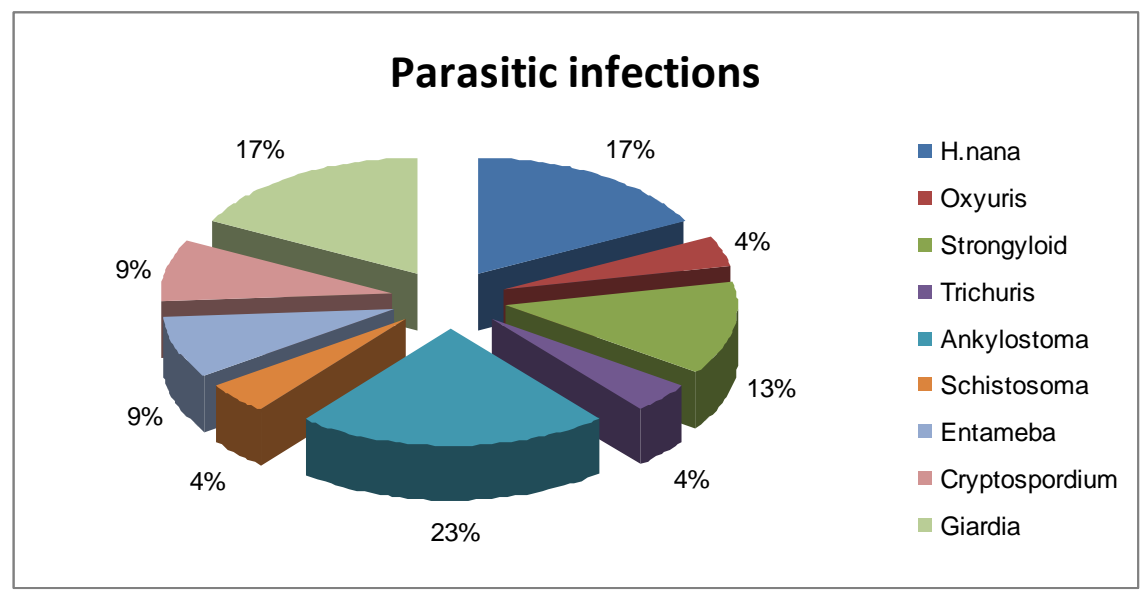

Fig. 1: Subtypes of parasitic infections and their prevalence among total infected children (46 cases).

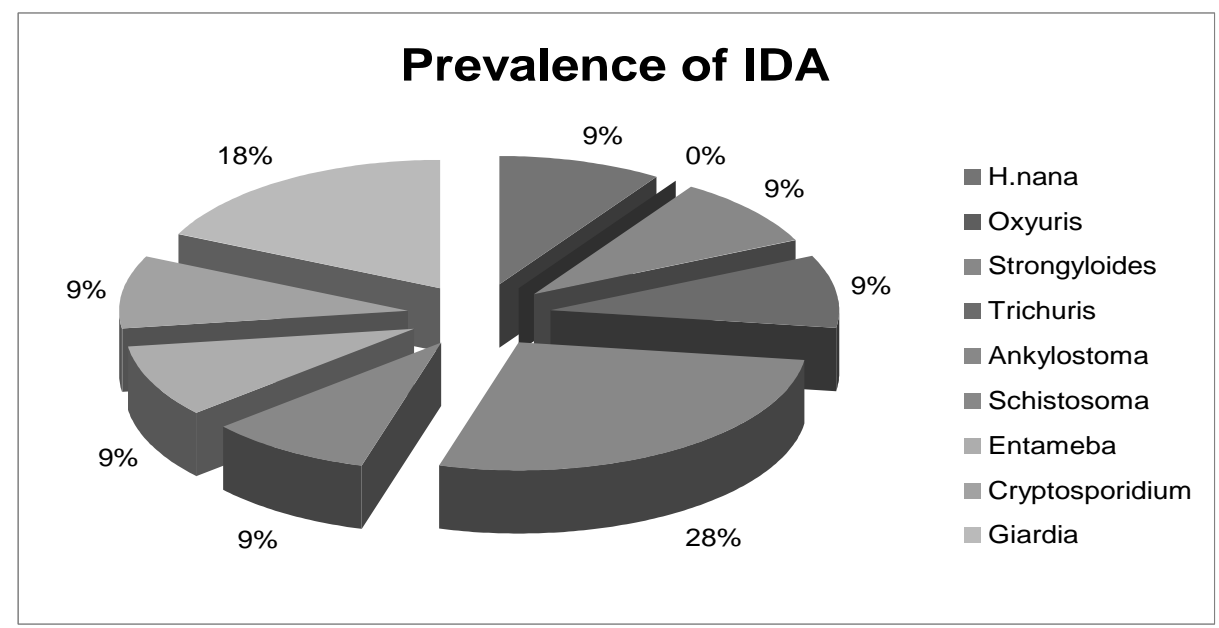

Fig (2): Prevalence of IDA in different subtypes of intestinal parasite 


\section{DISCUSSION}

In developing countries, intestinal parasitic infections are one of the most prevalent infections and also, have highly spread among school aged children [13].

Intestinal parasitic infestations are considered as a serious public health problem as it causes iron deficiency anaemia, growth retardation in children, and other physical and mental health problems [14].

Bad effect of intestinal parasitic infestations on child iron status was observed by Hesham et al. [15] who linked intestinal parasitic infestations with significant reduced mean haemoglobin levels in children.

Prevention of iron deficiency anemia can improve performance in school, avoid behavioral alterations, and assure better growth. Longitudinal studies reported that children who are anemic in infancy continue to have poor cognition, longlasting adverse effects on hearing and visual function, poor school achievement and more behavioral problems [16].

This cross-sectional survey was carried out at El Kalige village, Dakahlia governorate to demonstrate the relationship between intestinal parasitic infections and iron deficiency anemia in a sample of children in this rural area in Dakahlia. Data showed an interaction between parasitic infections, haemoglobin level suggesting that parasites affect serum iron level of surveyed children.

This study was performed on 102 children (44 males, 58 females) aged 6- 12 years. The results reported that the prevalence of parasitic infections at this rural area was 37\% (47.4\% for males, $52.6 \%$ for females) (Table 1). This was in accordance with Sah et al. [17] who recorded that the prevalence of intestinal parasitic infection was $31.5 \%$ in a study performed on 147 school children attending the primary school in Nebal. The prevalence of parasitic infection was reported by Amare et al. [18] was lower than our results $(22.7 \%)$ in their study on school children in Gondar, Ethiopia.

The study performed by Hegazy et al. [19] on 500 preschool children aged 2-6years in Damanhur city, revealed that overall prevalence of parasitic infections was 51.8\%. Also Worku et al. [20] reported parasitic prevalence $55.6 \%$, both results were greater than our study (37\%) (Table1) .

The explanation for this result is due to improved sanitation which is the only definitive intervention to eliminate parasitic infection [21]. Sanitation in this village includes sewage systems since 1995 which helps the prevention of contamination of soil and water and prevent transmission of parasitic diseases. It is also due to periodic anti helminthic therapy. Anti helmintic treatment reduced morbidity by decreasing the worm burden. Regular chemotherapy in high-risk groups can reduce the levels of infection and also, result in immediate improvement in the growth and the health of the children [22]. Anti-helminthic therapy is given regularly at the start of each school year by Primary Health Care Unit in this village. Health education also participates in the reduction of the prevalence of parasitic infections. Achievement of reduction of infection and reinfection can be done by encouraging healthy behaviors [23].

Our results reported higher parasitic infection in females $(52.6 \%)$ more than males $(47.4 \%)$ but with insignificant difference (Table 1), this was in agreement with Rayan et al. [8] who found a higher parasitic infection in females $(59 \%)$ more than in males (41\%) in a study up on 195 rural school children. On contrast, Pradhan et al. [13] showed different result as the higher parasitic infection was in males (28.2\%) compared with females $(20.2 \%)$. This is explained by the presence of other environmental or behavioral factors other than the gender in parasitosis. Generally, the high risk of infection in male is due to the increased mobility of the male, while in female is due to more soil contact during growing vegetables and eating raw vegetable during preparing food [17].

This study reported that, the prevalence of anemia in all selected children was $51 \%$ (table 2).This was in accordance with Al-Mekhlafi et al. [24] who reported that the prevalence of anemia was $48.5 \%$ in a study was done on 241 school children (7-12) years in Pos Betau, Malaysia. Our result was higher than the result of a survey conducted by Ngui et al. [25] who reported overall prevalence of anemia $26.2 \%$ and Oliveira et al. [26] also found lower results than our result (21.6\%). On contrast, Nabakwe et al. [27] found that anaemia was extremely high (92\%) in Kenya, which could be attributed to the 
increase in the incidence of malaria in the area of the study.

Our study reported a high prevalence of anemia in infected children $(52.6 \%)$ compared with noninfected $(50 \%)$ ( table 1,2). This was in agreement with a study conducted by Hesham et al. [15] to assess the relationship between intestinal parasites and nutritional status in Thailand among 343 children, who showed that, the incidence of anemia was high among the infected children $(59 \%)$ than non-infected children $(42 \%)$. Hegazy et al. [19] also reported that prevalence of anemia was higher in infected children (48.6\%) compared with non-infected (28.8\%). It affects $20 \%$ to $50 \%$ of the world's population and it spreads among young children [28].

This study recorded that overall, $51 \%$ of children were anemic $(\mathrm{Hb}<11.5 \mathrm{~g} / \mathrm{dl})$. The prevalence of IDA was $45 \%$, which accounted for $88.5 \%$ of the anemic cases (Table 2). Globally, these results were in agreement with the data showed by WHO that, in developing countries, the prevalence of IDA is up to $48 \%$ of school-age children [29]. This was in accordance with Aini et al. [30] who reported that overall, $41.5 \%$ of children were anemic and $36.5 \%$ had IDA, which accounted for $88 \%$ of anemia in these children. On the other hand, lower result was conducted by Ngui et al. [31] on a total 550 school children aged 7 - 12 years, $26.2 \%$ were anemic and $16.9 \%$ with IDA .

Our study reported that IDA was slightly highly non-significant among infected children with $47.3 \%$ compared with both non infected $(43.8 \%)$ and all selected children $(45 \%)(\mathrm{p}=0.962)$ (Table 2 ). This is explained by the fact that blood loss (mostly occult bleeding), reduced appetite, impaired digestion, and malabsorption may be the reasons of poor iron status and iron deficiency anemia that are frequently observed in children suffering from intestinal parasitic infestations [32].

In our study parasitic infection is sub classified into 3 major group, helminthes, protozoa and mixed infection. Helminthic group (22), Protazoa group (8) and 8 cases mixed protozoa and helminthes. Overall helminthes infection were more prevalent $22 \%$ (22/102) compared with both protozoa infection $8 \%(8 / 102)$ and mixed infection 8\% (8/102) (Table 3). This coincided with Oliveira et al. [26] who reported that the prevalence of infection by helminths was higher than that of protozoa $(24.1 \%, 13.4 \%)$ in the studied children. While mixed coinfection by both helminthes and protozoa occurred in $6.7 \%$. Different result was conducted by Pradhan et al. [13] showing that the protozoal infection was higher than of the helminthes and mixed infection (17.5\%, 4.6\%, 1.5\%, respectively). Sah et al. [17] also found that, the infection by helminthes $(13 \%)$ and of protozoa $(18.5 \%)$ from the total population of the study.

Anemia was highly non-significantly prevalent in helminthes infection (54.5\%) compared with both protozoan and mixed infection (50\% each) (table3). This coincide with Jardim-Botelho et al. [33] who reported increase prevalence of anaemia associated with helminth infection compared with both protazoal and mixed infection. Also Alemu et al. [34] showed that helminth parasites was the obvious cause of high anemia prevalence compared to individuals with protozoa and mixed infections $(\mathrm{P}<0.0001)$.

Among the helminthes, the highest incidence was Ancylostoma duodenale (33.3\%), followed by Hymenolepis nana (26.6\%) (Fig. 1). This coincides with Jardim-Botelho et al. [33] who reported also a high incidence of Ancylostoma duodenale (69.8\%) with the majority of individuals harbouring helminthes infections. This is in contrast with Gyawali et al. [35] and Khanal et al. [36] on studies conducted on school children of Nepal. These studies have found Ascaris lumbricoides and Trichuris trichiura as the commonest intestinal helminthes in school children of Nepal.

Among the intestinal protozoa, Giardia lamblia was the first one, followed by Entamoeba histolytica and cryptosporidium (fig 1). This was in accordance with Pradhan et al. [13] who found that Giardia lamblia was the most common (58.6\%) among protazoal infection. On contrast, Rayan et al. [8] reported different result as Entamoeba histolytica had the highest prevalence $(25.3 \%)$, then Giardia lamblia $(17.9 \%)$.

In our study, Ancylostoma duodenale was the most common parasites associated with IDA in anemic infected children $28 \%$ (6/22),followed by Giardia lamblia 18\% (4/22) then Hymenolepis nana, Strongyloides stercoralis, Trichuris trichiura, Schistosoma mansoni, cryptosporidium 9\% (2/22) each (fig 2). This coincides with Aini et al. [30] who showed that the depletion of iron stores was mainly caused by Ancylostoma duodenale infection. It was reported that anaemia was more common among intestinal parasitic 
infected especially, giardiasis. This study was performed to show the association between haemoglobin, serum iron, serum ferritin concentrations in Orang Asli children living in endemic areas of intestinal parasitic infections in Malaysia.

Jonker et al. [37] also found that A. duodenale was $(32.1 \%)$ from the severe cases of anemia and $(23.5 \%)$ from the non-severely ones. The explanation for this result may be that the severity of disease is associated with increase of the intensity of the hookworm infection. Due to the blood loss from the bowel mucosa of the infected host caused by the attachment and feeding of the adult hookworms upon it leading to iron deficiency and anemia. Blood loss caused by $A$ duodenale is 2 to 10 times more than by N.americanus.

All studies which were performed upon the prevalence of hookworm infection, observed that hookworm infection was a strong predictor of IDA and anaemia in school children. In addition, anaemia became worst in heavy hookworm infection. Furthermore, it has been reported that children from high prevalence of Ancylostoma duodenale areas had significantly worse IDA than children from low prevalence areas [38].

Many results reported that Giardia infection was associated with lower iron levels. The prevalence of IDA reached $74.4 \%$ among pre-school children infected with giardiasis and coming from a rural area of Egypt [39]. Giardia lamblia infection had an adverse effect on the growth and the hemoglobin level of the children as a result of damage to the intestinal mucosa and malabsorption [40].

\section{CONCLUSION}

The results showed that, the prevalence of parasitic infections is still high among the rural children of Egypt. Iron deficiency anemia is highly prevalent in school-children especially, in children who have parasitic infestations. This study emphasizes the importance of health education, good sanitation and personal hygiene, good cooking of food, safe water supply. And also, Screening for intestinal parasitic infections and appropriate treatment even they were asymptomatic, could be an important part of the program for anemia control in less developed countries.
Funding: None.

Conflicts of interest: None.

Ethical approval:Approved.

\section{REFERENCES}

1. Amare B, Ali J, Moges B, Yismaw G, Belyhun Y, Gebretsadik S, et al. Nutritional status, intestinal parasite infection and allergy among school children in northwest Ethiopia. BMC Pediatr; 2013, 13(7): 13-27.

2. World Health Organization/WHO. The world health report 2002: reducing risks, promoting healthy life. Geneva, 2002.

3. Yones DA, Galal LA, Abdallah AM, Zaghlol KS. Effect of enteric parasitic infection on serum trace elements and nutritional status in upper Egyptian children. Trop Parasitol; 2015, 5(1): 29-35.

4. Le HT, Brouwer ID, Verhoef H, Nguyen KC, Kok FJ. Anemia and intestinal parasite infection in school children in rural Vietnam. Asia Pac J Clin Nutr; 2007, 16(4): 716-23.

5. World Health Organization. World wide prevalence of anaemia 1993-2005. World Health Organization, Geneva, 2008.

6. Iqbal MM, Malik BA. Parenteral iron therapy in malnourished children. Pakistan Armed Forces Med J; 2006, 56(6): 271-275.

7. Rasmuussen SA, Fernhoff PM, Scanlon KS. Vitamin B12 deficiency in children and adolescents. Journal of Pediatrics, 2001, 138, 1017.

8. Rayan P, Verghese $S$, McDonnell PA. Geographical location and age affect the incidence of parasitic infestations in school children. Indian J Pathol Microbiol; 2010, 53:498-502.

9. Daniel AD. Sample size calculation in medical studies. Gastroenterol Hepatol Bed Bench; 1999, 6(1): 14-17.

10. Monica C. District laboratory practice in tropical countries Part 2. Cambridge Low Price Editions, Cambridge University Press, 2000, 207-212 and 253-266.

11. Garcia LS, Bruckner DA. Diagnostic medical parasitology Washington. American Society for Microbiology, DC, 1993.

12. Dacis, J., Lewis, D. Practical hematology. 8th Edition, Churchill Livingstone, London, 2006, 27-30.

13. Pradhan P, Bhandary S, Shakya PR, Acharya T, Shrestha S. Prevalence of intestinal parasitic infections among public school children in a rural village of Kathmandu Valley. Nepal Med Coll J; 2013, 16(1): 50-53. 
14. Kim BJ, Ock MS, Chung DI, Yong TS, Lee KJ. The intestinal parasite infection status of inhabitants in the Roxas city, the Philippines. Korean J Parasitol; 2003, 41(3):113-115.

15. Hesham MS, Edariah $A B$, Norhayati $M$. Intestinal Parasitic Infections and Micronutrient Deficiency: A Review. Med J Malaysia; 2004, 59(2):284-293.

16. Lozoff B, Jimenez E, Hagen J, Mollen E, Wolf AW. Poorer behavioral and developmental outcome more than 10 years after treatment for iron deficiency in infancy. Pediatrics; 2000, 105(4): 10-15.

17. Sah RB, Bhattarai $S$, Yadav $S$, Baral R, Jha N, Pokharel PK. A study of prevalence of intestinal parasites and associated risk factors among the school children of Itahari, Eastern Region of Nepal. Trop Parasitol; 2013, 3(2):140-144.

18. Amare B, Ali J, Moges B, Yismaw G, Belyhun Y, Gebretsadik $S$, et al. Nutritional status, intestinal parasite infection and allergy among school children in northwest Ethiopia. BMC Pediatr; 2013, 13(7): 13-27.

19. Hegazy AM, Younis NT, Aminou HA, Badr AM. Prevalence of intestinal parasites and its impact on nutritional status among preschool children living in Damanhur City, El-Behera Governorate, Egypt. J Egypt Soc Parasitol; 2014, 44(2):51724.

20. Worku N, Erko B, Torben W, Belay M, Kasssu A, Fetene T, et al. Malnutrition and intestinal parasitic infections in school children of Gondar, North West Ethiopia. Ethiop Med J; 2009, 47(1):9-16.

21. Asaolu S O, Ofoezie I E. The Role of Health Education and Sanitation in the Control of Helminth Infections. Acta Tropica; 2003, 86(2):283-294.

22. Albonico M, Smith PG, Ercole E, Hall A. Rate of Reinfection with Intestinal Nematodes after Treatment of Children with Mebendazole or Albendazole in a Highly Endemic Area. Transactions of the Royal Society of Tropical Medicine and Hygiene; 2005, 89(5): 538-541.

23. Hotez PJ, Brooker S, Bethony JM, Bottazzi ME, Loukas A, Xiao S. Hookworm infection. New England Journal of Medicine; 2004, 351(8):799_ 807.

24. Al-Mekhlafi MH, Surin J, Atiya AS, Ariffin WA, Mahdy AK, Abdullah HC. Anaemia and iron deficiency anaemia among aboriginal schoolchildren in rural Peninsular Malaysia: an update on a continuing problem.Trans $R$ Soc Trop Med Hyg; 2008, 102(10):1046-1052.

25. Ngui R, Ravindran S, Ong DB, Chow TK, Low $\mathrm{KP}$, Nureena ZS, et al. Intestinal parasitic infections and the level of immunosuppression in HIV seropositive individuals with diarrhoea in Kilimanjaro, Tanzania: A cross-sectional study. PLoS Negl Trop Dis; 2013, 18(3):122-139.
26. Oliveira D, Ferreira FS, Atouguia J, Fortes F, Guerra A, Centeno-Lima S. Infection by Intestinal Parasites, Stunting and Anemia in School-Aged Children from Southern Angola. PLoS One; 2015, 10(9): e0137327.

27. Nabakwe EC, Lichtenbelt WV, Ngare DK, Wierik M, Westerterp KR, Owino OC. Vitamin a deficiency and anaemia in young children living in a malaria endemic district of western Kenya. East Afr Med J; 2005, 82(6):300-306.

28. Sungthong R, Mo-suwan L, Chongsuvivatwong $\mathrm{V}$. Effects of hemoglobin and serum ferritin on cognitive function in school children. Asia Pacific. Clin Nutr; 2002, 7(4): 245-255.

29. WHO. Iron deficiency anaemia: assessment, prevention, and control. World Health Organization, Geneva, 2001.

30. Aini P N, Al-Mekhlafi H M, Azlin M, Shaik A, Sa'iah A, Fatmah MS, Iet al. Serum iron status in Orang Asli children living in endemic areas of soil-transmitted helminths. Asia Pac J Clin Nutr; 2007, 16(4):724-730.

31. Ngui R, Lim YA, Chong Kin L, Sek Chuen C, Jaffar S. Association between anaemia, iron deficiency anaemia, neglected parasitic infections and socioeconomic factors in rural children of West Malaysia. PLoS Negl Trop Dis; 2012, 6(3):23-33

32. Binay KS, Lubna AB. Association of anemia with parasitic infestation in Nepalese women: results from a hospital-based study done in eastern Nepal. Journal of Ayub Medical College; 2005, 17(3): 5-9.

33. Jardim-Botelho A, Brooker S, Geiger SM, Fleming F, Souza Lopes AC, Diemert DJ, et al. Age patterns in undernutrition and helminth infection in a rural area of Brazil: associations with ascariasis and hookworm. Trop Med Int Health; 2008, 13(4):458-67.

34. Alemu A, Shiferaw Y, Ambachew A, Hamid H. Malaria helminth co-infections and their contribution for aneamia in febrile patients attending Azzezo health center, Gondar, Northwest Ethiopia: a cross sectional study. Asian Pac J Trop Med; 2012, 5(10):803-809.

35. Gyawali N, Amatya R, Nepal HP. Intestinal parasitosis in school going children of Dharan municipality, Nepal. Trop Gastroentero; 2009, 30(7): 145-147.

36. Khanal L, Choudhury D, Rai SK. Prevalence of intestinal worm infestations among school children in Kathmandu, Nepal. Nepal Med Coll J; 2011, 13(2): 272-274.

37. Jonker FA, Calis JC, Phiri K, Brienen EA, Khoffi $\mathrm{H}$, Brabin BJ, et al. Real-time PCR demonstrates Ancylostoma duodenale is a key factor in the etiology of severe anemia and iron deficiency in Malawian pre-school children. PLoS Negl Trop Dis; 2012, 6(3)12-22. 
38. Guyatt HL, Brooker S, Kihamia CM, Hall A, Bundy DA. Evaluation of efficacy of schoolbased anthelminthic treatments against anaemia in children in the United Republic of Tanzania. Bulletin of the World Health Organization ; 2001, 79(8); 695-703.

39. Hussein EM, Zaki WM, Ahmed SA, Almatary AM, Nemr NI, Hussein AM. Predominance of Giardia lamblia assemblage A among iron deficiency anaemic pre-school Egyptian children. Parasitol Res; 2016, 115(4):1537-1545.

40. Botero-Garcés JH, García-Montoya GM, Grisales-Patiño D, Aguirre-Acevedo DC, Alvarez-Uribe MC. Giardia intestinalis and nutritional status in children participating in the complementary nutrition program, Antioquia, Colombia,May to October 2006. Rev Inst Med Trop Sao Paulo; 2009, 51(8): 155-162. 